\title{
Organizational Factors for Exploration and Exploitation
}

\author{
Sharadindu Pandey (I), RRK Sharma (2)
}

\begin{abstract}
The Purpose of the paper is to develop a conceptual framework which suggests a relationship between organisational factors and exploratory and exploitative innovation types. We searched major databases like ABI/INFORM global, EBSCO, Elsevier's science direct, Springer link and Emerald full text. Most of studies were included from published sources. We explored the literature of organisational culture, motivational bases of the rewards system and leadership values which are responsible for increasing creative and productive output. Our study has attempted to identify common patterns and themes in the literature regarding the drivers that increase both sides of the organisational creativity. The paper discusses the role of culture, system and styles in the initiation and implementation phases of the innovation called herein exploitative and exploratory innovation.
\end{abstract}

Keywords: Exploration, Exploitation, Creativity, Culture, Leadership, Reward system.

(I) Indian Institute of Technology Kanpur (India) E-mail address: sharadp@iitk.ac.in.

Full international contact details: C-2, SBRA, IIT Kanpur (UP) India Pin-2080I6, Phone -9I-99563।I283

(2) Indian Institute of Technology Kanpur (India) E-mail address: shardp I @rediffmail.com

Full international contact details: IME Department, IIT Kanpur (UP) India Pin-2080I6 


\section{Introduction}

Researchers classify innovation as two separate set of activities viz exploration and exploitation. Benner \& Tushman (2002) and Jansen (2005) differentiate between 'exploitative Innovations' which involve 'improvements in existing components and architectures and build on the existing technological trajectory' and 'exploratory innovations' which involve 'a shift to a different technological trajectory'. In addition to this way of classification, authors have also indicated another dimension to distinguish between these two activities. Coombs (1996) suggested two sides of R\&D activities; Investment mode where these activities are concerned with developing technological capabilities of organizations, and harvesting mode where R\&D works with other functions of the organization to exploit special services for customers. Recently, $\mathrm{He}$ and Wong (2004) mention, an explorative innovation strategy to contain 'technological innovation activities targeting new product- market domains and 'exploitative innovation strategy' to contain 'technological innovation activities for ameliorating existing product-market. Authors of the strategic management describe exploration, in terms of competence building (Sanchez et al., 1996) or competence definition (Floyd \& lane, 2000), and exploitation, in terms of competence leveraging (Sanchez et al., 1996) or competence deployment (Floyd \& Lane, 2000). Cavone et al (2000) indicates key characteristics of experimental programmes is a continuous search for new technological solutions and a learning process aiming to enhance the firm's knowledge base and exploitation programme is to create value through current activities and to innovate by exploiting the skills embedded in a firm's human resource and technical systems. Some authors relate these two activities as development and implementation stage of the innovation. First stage is characterized by exploration activities such as risk taking, searching for alternatives (Duncan, 1976), and discovery (Cheng \& Van De Ven, 1996), while second stage is characterized by exploitation activities such as testing (Cheng \& Van De Ven, 1996), refining and implementing (Duncan, 1976) the innovation.This distinction between experimental and exploitation activities is conceptually different from the traditional classification of R\&D activities in research (basic or applied) and product development (Cavone et al, 2000).

\section{Literature background}

\section{I Conflict between exploration and exploitation ac- tivities}

Both exploitation and exploration are crucial for ongoing operations of organizations and organizational change (Crossan et al. 1999). However, Christensen (1997) suggested that due to the disruptive nature of the technology; experimenting units must be completely separated from exploiting units. In the Stage models of innovation, (Kanter, 1988) shows that the mix of activities required during the innovation process which varies greatly from stage to stage so as innovative behaviour which has been discussed until now idea generating (Bask I991) extends to a broad range of other types of behaviour which combine to result the final innovative outcome. Despite the strategic management thinkers endorse ambivalent capabilities for an organizational excellence, organizational stimulants for exploration and exploitation are of such a conflicting nature that possibility of their co-existence at single space and time is quite perplexed. Both the activities are separated on the basis of location, time and structure within organization. Separation of exploration and exploitation by location can be found in studies on 'structural ambidexterity' (Benner \& Tushman, 2003; O'Reilly \& Tushman, 2004).Ambidextrous organizational forms are 'composed of highly differentiated but weakly integrated sub-units' (Benner \& Tushman, 2003). While the exploration units are small and decentralized with loose cultures and processes, the exploitation units are larger and more centralized with tight cultures and processes (Benner \& Tushman, 2003). Both exploitation and exploration involve a trade-off, because firms with limited available resources may not be able to afford to exploit and explore simultaneously. Such a trade-off reflects a 'key dilemma' for organizations that aim to enhance both 'adaptation to exploit present opportunities' and their 'adaptability to exploit future opportunities' at the same time (Isobe, 2004).

Duncan (1976) proposed a model for designing organizations for initiating and implementing innovations. The initiation stage of the innovation process has an organizational structure featured by a high degree of complexity, low formalization, and low Centralization. The implementation stage of the innovation process, however, reflects an organizational structure featured by a low degree of complexity, high formalization, and higher centralization. As initiation and implementation follow each other sequentially, Duncan (1976) suggests that organizations should change their organization structure correspondingly over time to match the changes. A review of the studies linking national culture and various innovative activities (Shane 1992, 1993, Herbig and Miller 1992, Kedia, Keller and Julian 1992, Nakata and Siva Kumar, 1996) suggests that certain cultural characteristics may have a greater propensity to support the varied innovatory activities. Kedia et al. (1992) clearly indicate that the managers should consider locating foreign R\&D units in countries where national cultures that promote high R\&D productivity. Units located in these countries would tend to outperform others. Shane (1992) concluded that some cultures have a comparative advantage in inventive activity that leads them to develop new technologies, ideas, and products. 
Nakata and Sivakumar (1996) take note that the possibility of some cultures being more adept than others in one phase of the new product development process, are more effective choices for that phase. Present study poses the research question about the different factors of organization culture as drivers of exploratory and exploitative innovation types.
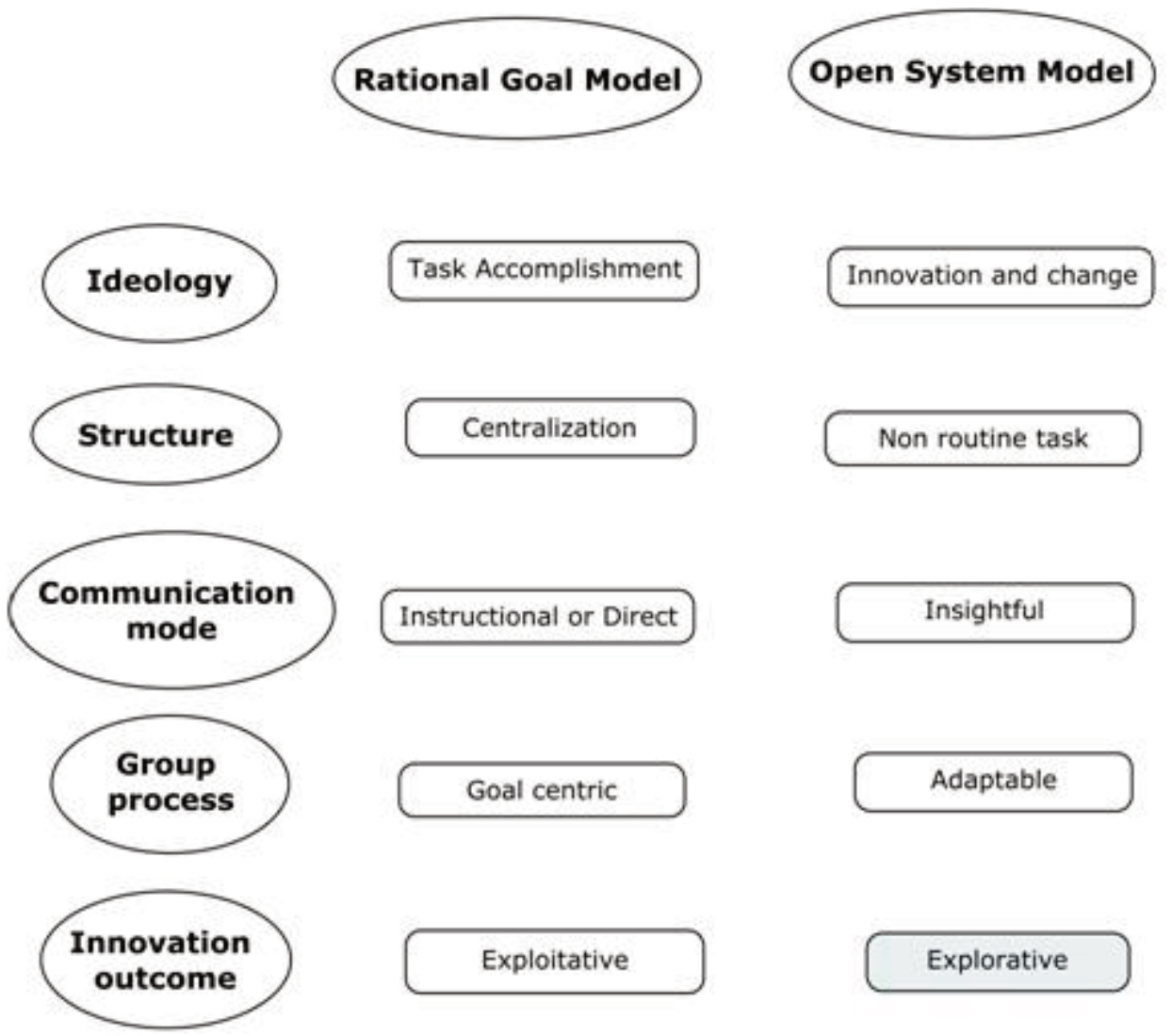

Innovation and change

Non routine task

Insightful

Diagram - I: Different models of organization factors

\subsection{Innovation, creativity and culture}

Innovation is affected by variety of contexts. A review of research on organizational innovation (Damanpour, 1991), identified factors which affect the management of innovation: type, stage and scope of innovation. Pavitt (I99I) took this note that different sectors e.g. scale intensive and science intensive have different priorities and characters. Likewise different stage in organization life cycle (Utterback, 1994) may affect the type of innovation for example new technology industry may be more involved in experimental innovation and matured industry players may be involved in exploitative innovation. Lundvell (1990) indicates that culture of the countries due to their differentials in institutions, policy supportive to the type of innovation may affect the nature of innovation. It has been supported by the research that a country like US has been advancing in the exploratory innovation and Asian country like Japan has been quite successful in the exploitative innovation. As explained by the Waterman et al. (1990), productive organization change is not simply a matter of structure though structure is important, it is also not simply as the interaction between strategy and structure, though strategy is critical too, it is infact the relationship between strategy, structure, system, style, skill and staff and something called super -ordinate goals. Within the organization, structure manifests along multiple dimensions including centralization of authority, hierarchy of influence and degree of role specification (Cooke and Szumal, 2000). These reasons may be prevalent where change of the structure constitutes a necessary but not sufficient lever for the cultural change (Cummings and Worley, I998). Hofstead (199I) takes note that organization culture has acquired the status similar to strategy, structure and control. A literature review (Read, 2000) of current research on the determinants of innovation indicate that the most important determinant identified for supporting creativity and innovative culture in the organisation was management support for innovation and an innovative culture. Martins and Terblanche (2003) found in their study that vision and mission are strategic determinants of organisational culture which 
influences innovation. Tushman and O'Reilly (1997) believed that organization culture is the soul of the organization innovation. A culture which supports creativity consolidates the platform for the innovation, be it management innovation or product innovation. O'Reilly (1989) asserts that the route of innovation is the extensively held and shared cultural norms in the organization which actively promote in the generation of the new ideas and doing new way of implementing the work. He further adds on that an organisation doesn't need to have very many strongly held values. In the firms like Wal-Mart, Marriott, Toyota and HP, a few core values are held but what is most important is how strongly it is held and spread among the members of the organization.

Hofstede (1997) discussed links between national culture dimensions and the management practice in detail. Deshpande et al. (1993) linked culture types to innovativeness. Using a synthesis of over 100 previous studies in organizational behaviour, sociology and anthropology, they defined four generic culture types: market culture, adhocracy culture, clan culture and hierarchical culture. Jaeger (1986) reported while commenting on the Hofstead's four dimensions of the culture that person in every society carry around mental programmes that guide their behaviour. He explains further that these programmes are conditioned in to members of given cultural groups by their common socialization and life experiences. Amabile (1988) explains that creativity requires a cognitive-perceptual style characterized by the ability to break mental set and explore new cognitive pathways. Under strong external pressures to complete a task, the individual is less likely to explore new pathways or suspend judgment. Rather he or she is likely to search for a solution that is adequate for the task at hand. With external pressure, productivity on tasks for which solutions are known may be enhanced, but the discovery of new solutions will be hindered. Exploratory and exploitative innovation can also be linked to the outcome of the convergent and divergent line of thinking. Convergent thinking tends to move toward a single solution to a problem and involves the generation of multiple ideas that are of the same general category (Mayer, 1992; Guilford, 1956). On the contrary, divergent thinking involves the generation of many ideas that are qualitatively different from one another. Divergent thinking is widely considered to be an important antecedent to creativity because creative solutions are defined as unique or original in nature (Amabile, 1983). As Amabile (1983) explains creativity is "A novel and appropriate, useful, correct, or valuable response to the task at hand and the task is heuristic rather than algorithmic." and the creative process is the interrelationship of three elements: person, task, and organization (Kao, 1991). It appears from the above thoughts that creativity or exploration is very much individualistic but dependent on the contextual factors. To flourish novelty, one needs outside support as well as certain self attributes. Roe (1963) found that Openness to experience, observance, tolerance of ambiguity, independent, needing autonomy, self-reliance willingness to take calculated risks, and persistence are the attributes required for the creative behaviour in the organization. In addition factors like Sensitivity to problems, fluency, flexibility, originality, and responsiveness to feelings, motivation, and freedom from the fear of failure (Raudsepp, 1983) very much affect the inventive behaviour.

\subsection{Rational goal model vs Open systems model}

Rational goal model is based on Barley and Kunda's (1992) system rationalism ideology. Scott (1992) views organisation as rational system which attains productivity and efficiency by goal setting and planning. He included three theories viz contingency theory (Burns and stalker, 196I), agency theory (Alchian and Demsetz, 1972) and transaction cost analysis (Ouchi, 1980). This ideology is based on the task achievement and the terms usually applied for this organisation is driven, goal oriented, achievers and focused (Zammuto et al, 2000). This organizational structure appears to be characterized in exploitative form of the innovation, because these organizations are driven by the goals. They have to constantly serve the demands of their focused markets. They usually involve in incremental innovations. Leadership in this type of organisation provides suitable direction and initiation required for making maximum performance out of their employees. Creative achievements defined through their novelty (Shalley, Gilson, and Blum, 2000) are supported by an open organizational culture. Open system model of the organisation challenges the assumptions of the Rational goal model. This model focuses on informal co-ordination and control system. Interpersonal relation in this type of organisation is characterized by trust, high employee morale, leader's benevolence to subordinates and low level of conflict. The term used for this type of organisation is innovative, aggressive, adaptable and entrepreneurial ((Zammuto et al, 2000). This model seems to be best fit for the exploratory units of the organisation. 


\begin{tabular}{|l|l|}
\hline $\begin{array}{l}\text { Small power distance societies } \\
\text { Hierarchy means inequality of roles, established for con- } \\
\text { venience } \\
\text { Subordinates expected to be consulted } \\
\text { Ideal boss is resourceful democrat }\end{array}$ & $\begin{array}{l}\text { Large power distance societies } \\
\text { Hierarchy means an existential inequality } \\
\text { Ideal boss is benevolent autocrat (good father) }\end{array}$ \\
\hline $\begin{array}{l}\text { Collectivist society } \\
\text { Value standards differ for in-groups } \\
\text { and out-groups : particularism }\end{array}$ & $\begin{array}{l}\text { Individualist society } \\
\text { Same value system applies to all } \\
\text { Other people seen as potential resources } \\
\text { Task prevail over relationship } \\
\text { Calculative model of employee-employer relationships }\end{array}$ \\
\hline $\begin{array}{l}\text { Feminine societies } \\
\text { Assertiveness ridiculed }\end{array}$ & $\begin{array}{l}\text { Masculine societies } \\
\text { Assertiveness appreciated } \\
\text { Ondersell yourself } \\
\text { Stress on life quality } \\
\text { Intuition }\end{array}$ \\
\hline $\begin{array}{l}\text { Stress on careers } \\
\text { Decisiveness }\end{array}$ \\
\hline $\begin{array}{l}\text { Weak uncertainty avoidance societies } \\
\text { Less formalization and standardization } \\
\text { Tolerance of deviance persons and ideas }\end{array}$ & $\begin{array}{l}\text { Strong uncertainty avoidance societies } \\
\text { Emotional need for rules-written or unwritten } \\
\text { More formalization and standardization } \\
\text { Intolerance of deviant persons and ideas }\end{array}$ \\
\hline
\end{tabular}

Table-I: Relating national culture dimensions with management Practice Source:Adapted from Hofstede (1997)

\section{Conceptual development}

\section{I Power distance}

Power distance refers to the extent to which a subordinate perceives discrepancies in his or her power relative to the power of his or her supervisor (Napier et al, 1993). According to Hofstead (1980), it connotes the extent to which power is unequally distributed in hierarchy. Authors supportive to the spatial separation of organization activities believes that, managers concerned to a certain hierarchical level (Floyd \& Lane, 2000; Prahalad and Hamel, 1990), function (De Leede at al., 2002), unit (Benner \& Tushman, 2003; Tushman \& O'Reilly, 1996) should focus either on exploration activities or on exploitation activities. Typically, production-units are strongly geared towards exploitation by focusing on operational efficiency. R\&D-units and marketing-units are more oriented towards exploration by engaging in unpredictable research projects, developing new products, and searching for and experimenting with new approaches to markets and customers (Volberda, 1998). Exploitation oriented firms where production process is dominant activity may look for the incremental innovation. It usually has mechanistic structure. Burns and Stalker (1964) and Damanpour (199I) found that formalization and centralization are the characteristics of mechanistic structures. Organization culture high in power distance tends to be highly centralized with several layers of hierarchy (Hofstead, 1996). Duncan (1976) argues that employees who have been involved in the non-routine tasks associated with innovation "are likely to initially resist more centralization in rules and procedures and decision making"-organizational changes necessary for high performance in the more routine, implementation stage. Fewer innovative ideas tend to be put forth in centralized organizations, implementation tend to be straightforward after the decision is made (Ulrich and Wieland, 1980). In the long run, it is likely that the decentralized organizations will produce more new ideas (Ulrich and Wireland, 1980). Abernathy (1978) suggested that a firm's focus on productivity gains inhibited its flexibility and ability to innovate. Pelz (1952) found that subordinate's satisfaction was higher when supervisors with high influence engaged in supportive behaviour by siding with employees rather than management, in comparison with supervisors without upward influence who engaged in the same supportive behaviour According to Tushman and O' Reilly (1997), management sensitive to the method of rewards and recognition will inspire personnel in their specific organisation to be more creative and innovative. Martin et al (2003) mention that culture of flexibility, moderate use of formal rules, decentralisation and shared decision making support the creativity within organisation. Formal rules and procedures can lead to in- 
creased efficiency and lower administrative costs (Ruekert et al., 1985) particularly in stable environment or those in which tasks are comparatively simple or repetitive. Formalization aims at integrating and using knowledge of the firm while reducing the need for organization members to acquire knowledge other than that provided by the system; they limit both the intensity and scope of knowledge acquisition by managers own initiative or authority (Weick, 1979). Arad et al (1997) reports that flat structures, flexibility will promote the creativity, and rigid control and order will hinder creativity and innovation. Information and the knowledge is a source of power. Communication system forms crucial mechanism for availing the expertise. Roy and Dhawan (2002) found in their study on Indian CSIR laboratories that better communication system can help scientist to update knowledge in their area of interest and can improve productivity Communication across the boundaries may be key to the generation of the new ideas (Christianson, 2000). In company like $3 \mathrm{M}$, a dense network of communication works across the boundaries. Companies with dense network of the horizontal communications tend to be better innovator than companies which communicate less (Nohria and Ghoshal, 1997). Winter and Szulanski (200I) illustrate that the exploration phase of a replication strategy characterized by discovering and developing a business model is facilitated by the acquisition of knowledge by the central organization from its outlets. The exploitation phase of a replication strategy characterized by stabilizing and leveraging the business model is facilitated by the acquisition of knowledge by the outlets from the central Organization. Learning through the acquisition of knowledge may be either exploratory reflected in an increase of the variety and broadness of the knowledge recipient's knowledge base (e.g. Inkpen, 1996; McGrath, 200 I; Nonaka, 1994; Tsai, 200 I), and/or exploitative reflected in an increase of the reliability and depth of the knowledge recipient's knowledge base (Adler et al., 1999; Levin, 2000). Based on the above discussion, we formulate our hypothesis as:

$\mathrm{HI}$ (a) Organizations Low in Power distance will generate high exploratory innovation.

HI (b) Organisations high in Power distance will generate high exploitative innovation.

$\mathrm{H} 2 \quad$ Flexibility in rules positively effects exploratory innovation.

H3 Knowledge inflow without boundary is positively associated with exploratory innovation

H4 (a) Management support based on intrinsic rewards will lead to high exploratory innovation.
H4 (b) Management support based on extrinsic rewards will lead to high exploitative innovation.

\subsection{Uncertainty avoidance}

Uncertainty has been defined as a contextual feature in any decision where it is not possible to assign an accurate probability distribution to the potential range of future outcomes (Knight, 197I). Hofstead (1980) defines this construct as extent to which organizational members do not tolerate unpredictability and ambiguity.Ambiguous situations are defined as a lack of sufficient information (Budner, 1962). A re-examination of the literature and recent research suggests that two contingencies exert a significant influence on organizational and management of innovation: uncertainty and complexity (Tidd, 1995; 1997).A review of $2 \mathrm{I}$ innovation research projects concludes that 'environmental uncertainty influences both the magnitude and the nature of innovation... (which) suggests that future research should adopt environmentally sensitive theories of organizational innovation by explicitly controlling for the degree and the nature of environmental uncertainty' (Damanpour, 1996). Perceptions of environmental uncertainty appear to affect the organization and management of innovation (Hauptman and Hirji, 1999; Souder et al, 1998).

As March (|99|) points out,"the certainty, speed, proximity, and clarity of feedback ties exploitation to its consequences more quickly and more precisely than is the case with exploration". He further puts it this way: "compared to returns from exploitation, returns from exploration are systematically less certain, more remote in time and organizationally more distant from the locus of action and adaptation." Because of the managers' preference for more certain and proximate returns over less certain and distant returns, organizations typically improve exploitation more rapidly than exploration (Lewin et al., 1999: 538; March, 1991: 73). Hofstede (1980) suggested that weak uncertainty avoidance relates to higher risk taking, thereby encouraging innovation, and Shane (1993) found that low uncertainty avoidance was associated with innovation. During periods of exploitative innovation, competition and environmental uncertainty is lower than during periods of discontinuity when rates of competition and levels of uncertainty within the technological environment change cyclically (Tushman \& Anderson, 1986). The hypotheses, supported by computer simulations, as developed by Garcia et al. (2003), for instance, illustrate that a focus on technology exploration over exploitation within a firm is favourable in times when competition is high, whereas a focus on technology exploitation over exploration is favorable in times when competition is low. Thus we may propose the hypothesis as: 
H5 (a)

innovation.

H5 (b) Uncertainty avoidance is high in exploitative

innovation.

\subsection{Individualistic and collectivist orientation}

Individualistic cultures focus on independence and personal identity whereas collectivistic cultures focus on interdependence and group harmony (Hofstede, 1984; Triandis, 1995). Bravery, creativity, self-reliance, solitude, and frugality are valued in individualistic cultures, whereas reciprocity, obligation, duty security, tradition, dependence, harmony, obedience to authority, equilibrium, and proper action are valued in collectivistic cultures (Triandis, 1989). Members of individualistic cultures strive for special recognition by achieving beyond the norms of the group; collectivists are more motivated to understand the norms for achievement in the particular context so as to meet that standard (Azuma, 1994). Nakata and Sivakumar (1996) proposed that individualism would support the initiation phase of new product development (versus collectivism supporting implementation). A methodological individualist argues that the whole is less than the sum of the parts so as to participate in any group; all individuals have to inhibit some of their qualities, capacities, and desires. Hence the group inhibits the full freedom and potential of the individual. The individual will almost have to comply with some of the constraints of the group, deal with the inevitable differences that may arise and otherwise either inhibit energy or divert it to group maintenance tasks. This energy would clearly be better spent focusing on one's own individual efforts (Montuory, 2000). As experience shows, groups and teams can be immensely frustrating and time consuming, dragging one and all down to the lowest common denominator. But they can also create opportunities for immensely rewarding, satisfying, and indeed exciting work (Bennis \& Bierderman, 1998; DeMasi, 199I; Montuori \& Purser, 1999; Purser \& Montuori, 1999). Although collectivistic values may promote feelings of harmony and cooperation, they may also extinguish the creative spark necessary for innovation (Goncalo and Staw, 2005). Pye (1985) writes that to the western mind, individualism is essential for aggressive, creative behaviour. This is somewhat ironic, since the reason often cited for adopting collectivistic practices is their ability to bring greater innovation to the organization (e.g., Tushman \& O'Reilly, 2002). Because a creative idea usually requires one to do something in a new or different way (Amabile, 1988), the greater the novelty of an idea the more likely will there be a departure from current beliefs and values of an organization. This is probably why organizations often regard the most innovative ideas as inherently threatening-- as something to be resisted by those who control both the resources and ideology of the firm (Frost \&
Egri, 199I; Nemeth, 1997).

A creative process necessitates the work groups engage not only in divergent thinking but also in convergent thinking (Moneta, 1994). Through convergent thinking, work group funnel down a set of ideas or opportunities in to manageable decisions from which to proceed implementation (Milliken et al, 2003). Hargadon (1999) argues that groups play a central role in organizational creativity. Bringing people who have different expertise and different type of training together will stimulate the new ideas (Dougherty, 1992). Research on team dynamics emphasizes the potential of interactions with others to motivate, stimulate interest, add complexity, and introduce competitive pressure - all of which can lead to enhanced individual and group creativity (Heerwagen, 2002). Conformity pressures can help maintain some level of group cohesion and may sometimes be necessary for the group to be productive, such pressures can also pose a limitation for groups that seek creativity (Goncalo and Staw, 2005). For example, research on minority influence suggests that dissent, even when wrong, actually causes groups to think more divergently and ultimately to solve problems more creatively (Nemeth \&Wachtler, 1983; Nemeth \& Kwan, 1985). Hansen et al. (200I) investigate how the type of a team's tasks (i.e. explorative versus exploitative tasks) mediates the effect of a team's network position on its performance. The study shows that network structures which have a positive effect on teams engaging in exploration tasks, have a negative effect on teams engaging in exploitation tasks, and vice versa. More specifically, the empirical findings indicate that exploratory teams benefit from a network structure characterized by many strong and non-redundant ties, whereas exploitative teams benefit from a network structure characterized by weakly tied contacts that are moderately interconnected. Tsai (200I) found that organizations group can produce more innovations if they occupy central network positions that provide access to new knowledge developed by other units, moreover, the empirical evidence from network research suggests that teams that are connected and embedded within social network of the organization can more readily garner support and resources that result in successful implementation of their innovative ideas. Rosenkopf and Nerkar (200I) show that when organizational and technological boundary spanning search increases, the firm's ability to explore, i.e. the ability to create new knowledge through recombining knowledge, increases. Local search on the other hand, i.e. search for solutions in the neighborhood of the firm's current expertise, increases the level of exploitation within the firm. March (199I) expected collectivistic organizations to be more adept at exploitation than exploration. Because of strong social pressures that coworkers are observing, rewarding and sometimes punishing employee behaviour, a collectivistic organization may be better able to mobilize people's efforts than an individualistic 
organization. As a result, there may be stronger motivation, more attention to detail, and less deviance from accepted business practices. McGrath (200I), in her study of 56 new business development project found that organizational learning related to exploration behaviour leading to creativity and innovation was more effective when operated with high degrees of autonomy. Zhou and Woodman (2003) emphasize upon further research to isolate the potentially crucial role of auton- omy and discretion in the perception of employee creativity. We derive following propositions:

H6 Individual activities are positively related to exploratory innovation.

H7 Group heterogeneity is positively associated with exploratory innovation.

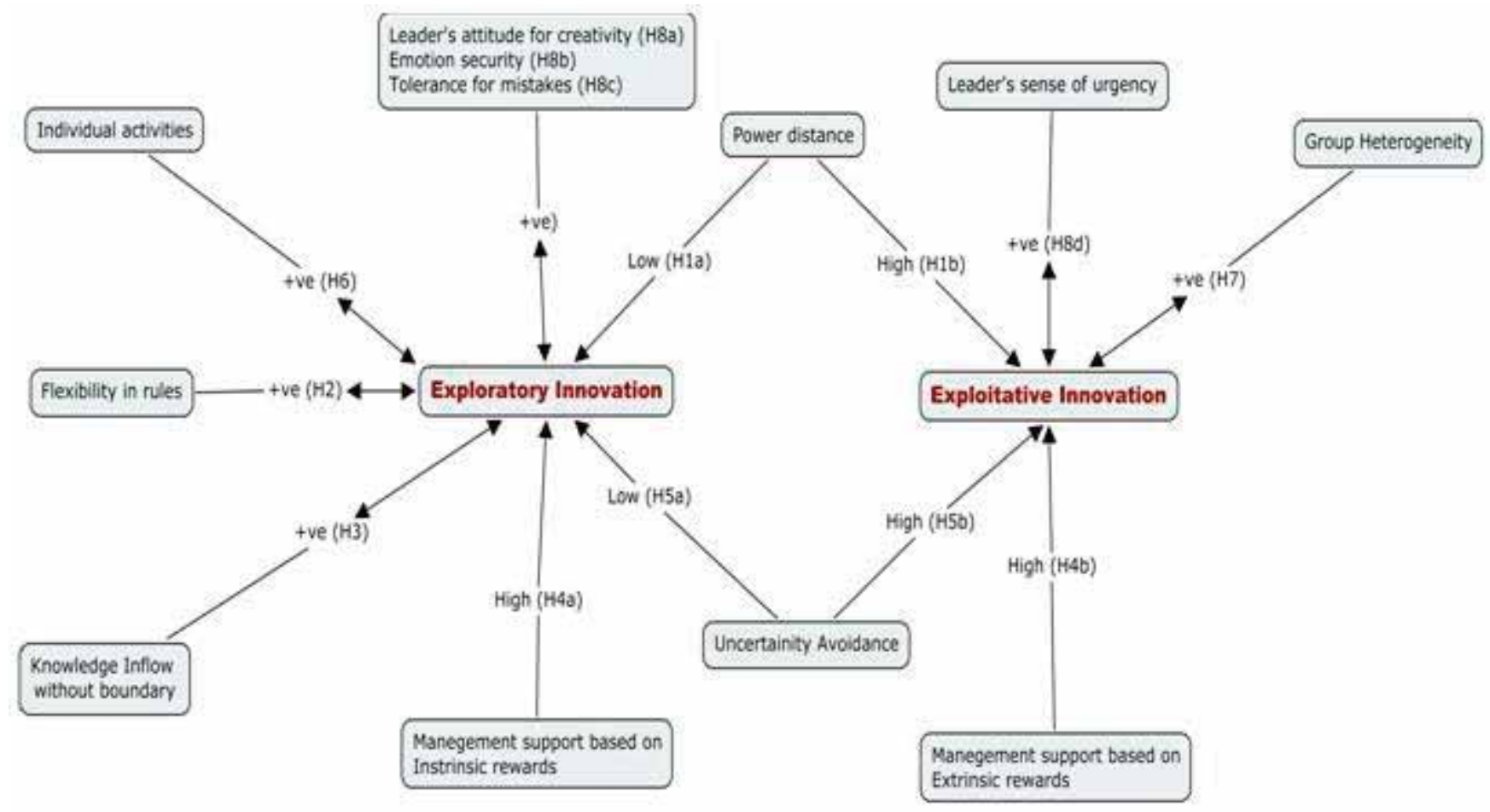

Diagram-2: Conceptual Model for organization variables for exploratory and exploitative innovation

\subsection{Leadership style}

Relationship between leader's behaviour and individual innovation has been investigated by transformational leadership, participative leadership, and leader-member exchange (LMX) theories (Dejong and Hartog, 2007), however leadership models for routine activities may not be generalized for the innovative activities (Mumford and Licuanan, 2004). LMX theory suggests that Leader and subordinate develop negotiated understanding about their roles. Some LMX subordinates are allowed enough decision latitude and are enjoying more time for the negotiated tasks (Graen and Cashman, 1975) and while others whose role making process is less successful, finally manage to perform routine task (Hen and Cashman, 1975). This model suggests the impact of the leaders-subordinate relation on innovativeness. Kotter (1990) asserts that leaders and managers are not different persons but they occupy different roles in the organisation. Leaders occupy more entrepreneurial role which is important for change. In a study among R\&D leaders and employees of a chemical firm,Tierney et al. (1999) found a positive relationship between high-quality relationship and creativity. Schein (1992) supports the notion that leadership can be more or less creative in different ways. He highlights six primary mechanisms that leaders use to embed a culture in an organisation:

I.What leaders pay attention to, measure and control?

\section{How leaders react to critical incidents}

3. How leaders allocate scarce resources

4. How leaders provide role modeling, teaching and coaching

5. How leaders allocate reward and status 
6. How leaders select, promote and/or excommunicate employees

According to Sternberg and his colleagues what type of creativity will emerge in an organisation depends in part on the leaders but also on the organizational environment. Amabile (1998) wrote about six managerial practices that enhance creativity. Her practices include:

I. Challenge. Matching the right person with the right job to play into their expertise and creative thinking skills.

2. Freedom. Intrinsic motivation and ownership is enhanced when people are free to approach their work in a way they choose.

3. Resources.

4. Work group features. Managers must create teams with a diversity of

Perspectives and backgrounds.

5. Supervisory encouragement. To sustain passion, people need to feel their work

matters and is important.

6. Organisational support creativity is truly enhanced when the entire organisation supports it.

Leader expression of enthusiasm or acceptance for innovation is one of the noted factors necessary for employee's motivation to be creative" (Tierney et al. 1999). For Instance Company like $3 \mathrm{M}$ has shown tremendous capability of innovation. Leaders herein recognize importance of the experimentation. A policy called 'I $5 \%$ policy' enables an employee to work on their curiousity driven agenda for up to $15 \%$ of their total productive time. Tolerance of conflict and handling conflict constructively are the values that support creative and innovative behaviour in the organisation (Mumford et al., 1997). In conflictful situations, Ting-Toomey and Kurogi (1998) found that people in individualistic cultures used direct and face-threatening strategies whereas people in collectivistic cultures used indirect and facesaving strategies. The speed of innovation can also promote or inhibit creativity and innovation (Martins and Terblanche, 2003). Based on above, we suggest following propositions:

H8 (a) Leader's attitude for creativity directly associated with the exploratory innovation.
H8 (b) Emotional security is positively related to exploratory innovation.

H8 (c ) Tolerance for mistakes positively associated with exploratory innovation.

H8 (d) Sense of Urgency positively related to exploitative innovation.

\section{Concluding discussion}

We provide conceptual framework here which is yet to be supported by data. This study has attempted to find patterns and themes in the literature regarding the drivers that increases both sides of the organisational creativity; exploratory and exploitative. We explored the dimensions of organisational culture, innovation management, Technology management and leadership style which are concerned for increasing creative output. As Ekvall (1996) suggests that people who are innovative or creative often have a low tolerance of rules and routine work, but have a high tolerance of ambiguity and lack of structure. Morris (2003) concludes in his literature review, "there appears, however, a general consensus among researchers in this field that: creativity is impeded by cultures that emphasise formal rules, respect for traditional ways of doing things, and clearly demarcated roles, creativity is encouraged by climates which are playful about ideas, supportive of risk taking, challenging and tolerant of ambiguity, democratic, participative leadership styles facilitate creativity while authoritarian styles inhibit it, creativity is enhanced by organisational structures and systems that are adaptable and flexible, access to, and effectively using, resources can be a stimulus for creativity and change". Martins and Terblanche (2003) speculate that creativity and innovation will flourish only under the right circumstances in an organization and under these circumstances, creativity and innovation can be influence by the several variables (These variables can be different for the innovation types that are exploratory or exploitative. Morris (2003) further explains that there is a systems view of creativity which suggests that creative outcomes are produced in a creative environment, where creativity as a culture is encouraged and rewarded. Present Study discusses those prominent factors which play as determinants of creativity culture and productive behaviour. 


\section{Selectd References}

AMABILE, T. M., 1988. A Model of Creativity and Innovation in Organizations. Research in Organizational Behavior, 10, pp. 123167.

ARAD. S. et al, 1997.A framework for the study of relationships between organizational characteristics and organizational behaviour. The Journal of Creative Behaviour, 3 I (I), pp. 42-58.

BARLEY, S.R. and Kunda, G., 1992. Design and Devotion: Surges of Rational and Normative Ideologies of Control in Managerial Discourse. Administrative Science Quarterly, 37 (3), pp. 383.

BENNER, M. J. and Tushman, M. L., 2003. Exploitation, exploration, and process management:The productivity dilemma revisited. Academy of Management Review, 28(.2).

CAVONE A. et al., 2000. Management style in Industrial R\&D organizations. European Journal of Innovation Management, 3 (2), Pp.59-7I.

CHRISTENSEN, C.M., 1997. The Innovators Dilemma: when new technologies cause great firms to fail. Harvard Business School Press, Boston, Massachusetts.

COOMBS, R., 1996. Core competencies and the strategic management of R\&D. R\&D Management, 26 (4).

CROSSAN, M. M. et al., 1999. An Organizational Learning Framework: From Intuition to Institution. Academy of Management Review, 24 (3), pp. 522-537.

DAMANPOUR, F., 1991. Organizational innovation: a metaanalysis of effects of determinants and moderators. Academy of Management Journal, 34, pp. 555-590.

DESHPANDE, R. et al., 1993. Corporate culture, customer orientation, and innovativeness. Journal of Marketing, 57, pp. 23-37.

DUNCAN, R.B., 1976. The ambidextrous organization: Designing dual structures for innovation. In Killman, R.H., Pondy, L.R. Slevin, and D. (Eds), The Management of Organization, New York: North Holland, I, pp. I67-188.

GARCIA et al., 2003. The role of knowledge in resource allocation to exploration versus exploitation in technologically oriented organizations. Decision Sciences, 34.

GONCALO, J. A. and Staw Berry M., 2005. IndividualismCollectivism and group creativity. Faculty Publications, Cornell
University, University of California, Berkeley.

GUPTA, A. et al., 2006. The Interplay between Exploration and Exploitation. Academy of Management Journal, .49 (4).

HE, Z. L. and Wong, P.K., 2004. Exploration vs. exploitation:An empirical test of the ambidexterity hypothesis. Organization Science, I 5 (4), pp. 48I-494.

HOFSTEDE, G., I99I. Cultures and Organizations: Software of the Mind. London: McGraw-Hill U.K.

HOFSTEDE G., 1997. Riding the Waves: A Rejoinder. International Journal of Intercultural Relations, 2 I (2), pp. 287-290.

HOLMQVIST, M., 2004. Experimental learning processes of exploitation and exploration. An empirical study of product development. Organization Science, 15.

ISOBE, T. et al., 2004. Exploitation, exploration, and firm performance: The case of small manufacturing firms in Japan. Working Paper.

JANSEN, J.J.P., 2005. Exploration and Exploitation in Technology Marketing: Building the Ambidextrous Organization. International Journal of Technology Marketing, I (5-6).

DE JONG, J.P.J. and Den Hartog, D.N., 2007.Leadership and employees innovative behaviour. European Journal of Innovation Management, 10 (I), pp. 4I-64

KAO, J., 1989. Entrepreneurship, creativity and organization. Prentice Hall, Englewood Cliffs, NJ.

KEDIA et al. 1992. Dimensions of national culture and the productivity of R \& D units, The Journal of High Technology Management Research, 3 , pp. I-18

MARCH, J.G., 199I. Exploration and exploitation in organizational learning. Organization Science, 2 (I), Pp. 7I-87.

MARTINS, E. C. et al., 2003. Building organizational culture that stimulates creativity and innovation. European Journal of Innovation Management, 6 (I).

MCGRATH, R.G., 200I. Exploratory learning, innovative capacity and managerial oversight. Academy of Management Journal, 44 (I), pp. ||8-|3|.

MORRIS, W., 2005. A survey of Organizational creativity. Available at www.leading-learning.co.nz. 
MUMFORD, M.D. and Licuanan, B., 2004. Leading for innovation: conclusions, issues, and directions. Leadership Quarterly, I5 (I), pp. |63-7I.

MCNAMARA, P. and Baden-Fuller, C., 1999. Lessons from the Celltech case: balancing knowledge exploration and exploitation in organizational Renewal. British Journal of Management, 10.

NAKATA, C. and Sivakumar, K., 1996. National Culture and New Product Development: An Integrative Review. Journal of Marketing, 60 (I), pp. I55-165.

PELZ, D. and Andrews, F., 1966. Autonomy, coordination and stimulation in relation to scientific achievement. Behavioural science, II.

POLITIS J.D., 2005. Dispersed leadership predictor of the work environment for creativity and productivity. European Journal of innovation Management, 8 (2).

PYE, L., 1985. Asian power and politics. The cultural dimensions of authority. Cambridge: Harvard.

SCHEIN, E. H., 1992. Organizational culture and leadership (2nd ed). San Francisco: Jossey-Bass.

SIDHU, J.S. et al. 2004. Exploring exploration orientation and its determinants: Some empirical evidence. Journal of Management Studies, 41.

TUSHMAN, M. L. and O'Reilly, C.A., 1997, Winning through innovation: A practical guide to leading organizational change and renewal. Boston, MA: Harvard University Press.

WINTER, S.G. and Szulanski, G., 200I. Replication as strategy. Organization Science, 12 (6), pp. 730-743.

VOLBERDA, H.W., 1996. Toward the Flexible Form: How to Remain Vital Hypercompetitive Environments. Organization Science, 7(4), pp. 359-374.

ZHOU, J. and Woodman, R.W., 2003. Managers' recognition of employees' creative ideas: a social-cognitive model. In Shavinina, V. (Eds), The International Handbook on Innovation, Elsevier Science Ltd,Amsterdam, pp.63I-40.

\section{About the Authors}

Sharadindu Pandey is a doctoral candidate at Indian Institute of Technology Kanpur, India. He is involved in the study of aligning strategy, culture and OD interventions. He has published papers in peer reviewed international journals and conference proceedings. His research interest includes culture and design of innovator organizations.

R.R.K. Sharma is Professor of Management at Industrial and Management Engineering Department at Indian Institute of Technology Kanpur, India. His research interest includes change management, innovation and operation management problems. 